\title{
POR UMA PEDAGOGIA DA AMOROSIDADE QUEER
}

\author{
POR UNA PEDAGOGÍA DE AMOROSIDAD QUEER
}

https://orcid.org/0000-0003-0848-5666 Danielle Ferreira Bastos A https://orcid.org/0000-0002-4157-0128 Marília Etienne Arreguy ${ }^{B}$

${ }^{\text {A }}$ Universidade Federal Fluminense (UFF), Niterói, RJ, Brasil

${ }^{\text {B }}$ Universidade Federal Fluminense (UFF), Niterói, RJ, Brasil

Recebido em: 30 abr. 2021 | Aceito em: 29 ag. 2021

Correspondência: Danielle Ferreira Bastos (daniellefbastos@hotmail.com)

\section{Resumo}

O presente artigo busca o entendimento dos desafios enfrentados pela criança queer ao lidar com a normatividade na escola, na busca por caminhos que não o da intolerância. $O$ texto argumenta que para a sobrevivência da criança queer, a amorosidade, conceito de Paulo Freire, pode subsidiar relações baseadas no diálogo. A construção argumentativa busca analisar a amorosidade através do campo psicanalítico bem como da filosofia da diferença. Por meio de uma vinheta escolar, é relatada uma cena em uma escola pública do Estado do Rio de Janeiro, a partir da qual concluímos que a amorosidade - não só voltada à criança, mas ao resgate de um lugar de autoridade do professor - propõe uma reflexão sobre a democratização das diferenças e sobre o rompimento da invisibilidade da criança queer.

Palavras-chave: teoria queer; criança queer; Paulo Freire; amorosidade; diferença.

\section{Resumen}

El presente artículo busca el entendimiento de los desafíos enfrentados por el niño queer al lidiar con la normativa en la escuela, en la búsqueda por caminos que no es de las intolerância. El texto argumenta que para la sobrevivencia del niño queer, la amorosidad, concepto de Paulo Freire, puede subsidiar relaciones basadas en diálogo. La construcción argumentativa busca analisar la amorosidad através del campo psicoanalítico tal como la filosofía de la diferencia. Por el medio de una escena escolar, es relatada una escena en una escuela pública del Estado del Río de Janeiro por la cual concluimos que la amorosidad - no es solo exclusiva a los niños, más el rescate de un sitio de autoridad del profesor - propone una reflexión sobre la democratización de las diferencias e sobre el rompimiento de la invisibilidad del niño queer.

Palabras clave: teoría queer; niño queer; Paulo Freire; amorosidad; diferencia. 


\section{Rompendo fronteiras por uma proposta educativa transdisciplinar}

Quanto mais se ama, tanto mais se ama.

Paulo Freire

Propomos aqui a conceituação sobre uma Pedagogia da Amorosidade Queer tomando como referencial teórico, Paulo Freire, patrono da educação brasileira, em especial através de seu conceito de amorosidade, que nos traz esse afeto solidário como uma força vital. A perspectiva freiriana, trata do (...) "amor pelas pessoas, mas também pelo mundo, pela vida, pelo lugar que se ocupa quando se educa" (...) [trata-se d'] "O amor político (...) de viver a vida para expandi-la e nunca para reduzi-la" (KOHAN, 2019, p. 123). A leitura da amorosidade freiriana será cotejada com autores da filosofia da diferença, bem como ponderada com noções da afetividade inconsciente oriundas do campo psicanalítico. Como referência crucial, recorremos também a Guacira Lopes Louro, teórica queer, que no Brasil tem sido a principal articuladora para pensar estratégias pedagógicas não-normativas. Suas pesquisas nos levam à diversas inquietações para pensar uma Pedagogia Queer. Em suas palavras:

\footnotetext{
Uma pedagogia e um currículo queer "falam" a todos e não se dirigem apenas àqueles ou àquelas que se reconhecem nessa posição-de-sujeito, isto é, como sujeitos queer. Uma tal pedagogia sugere o questionamento, a desnaturalização e a incerteza como estratégias férteis e criativas para pensar qualquer dimensão da existência (LOURO, 2008, p.52).
}

Como recurso metodológico, utilizamos a vinheta escolar ${ }^{i}$, representada por uma forma de narrativa ficcional de que dispomos para descrever uma cena em um dia de vivência de uma professora junto à sua turma de Educação Infantil em uma Creche e Pré-Escola que não identificaremos, justamente por entender que se trata de uma situação-padrão, no sentido de corriqueira e generalizável, cujo anonimato é preservado através do teor ficcional atribuído ao "caso" relatado na vinheta.

Assim, o presente trabalho tem como objetivo, refletir sobre as contribuições do conceito de amorosidade de Paulo Freire junto aos estudos queer de Guacira Lopes Louro para a inspiração, defesa e incentivo à implementação de uma Pedagogia da Amorosidade Queer. Tal processo não se potencializa sem a reflexão sobre aspectos inconscientes, pois em sintonia com a ideologia queer, tudo o que é estranho, diferente, esquisito, inominável pode ser caracterizado como fora da norma, causando uma inquietante estranheza (FREUD, 1919) que não pode simplesmente ser eliminada, pois ataca o sujeito tanto das profundezas de seu inconsciente quanto das representações imaginárias, simbólicas e reais que constituem esse grande Outro não barrado que nos determina (LACAN, 1966/1998). O sujeito queer representa 
esse estranhamento que não cessa de nos incomodar, de nos fazer rever nossas posições frequentemente estereotipadas; essas crianças apresentam algo de diferente, esquisito, estranho, que "incomoda", obrigando os atores escolares a saírem de posições típicas e enquadradas, tanto oriundas do senso comum quanto de certa ilusão psicopedagógica (LAJONQUIÈRE, 2009) como se fosse possível pedagogizar o desejo do outro. Nas palavras de Guacira Lopes Louro: "como um movimento que se remete ao estranho e ao excêntrico pode articular-se com a educação, tradicionalmente o espaço da normalização e do ajustamento? (...) Como traduzir a Teoria Queer para a prática pedagógica?” (LOURO, 2008, p. 47). Seria possível repensar o "normal" sem olharmos profundamente para os preconceitos histórica e inconscientemente arraigados em nós mesmos através de práticas educacionais excludentes e estigmatizantes?

\section{Uma vinheta escolar entre a esquisitice e estranhamento}

Apresentaremos uma cena ainda considerada excêntrica: na sala de aula de uma turma de pré-escola, com crianças $^{2 \mathrm{ii}}$ na faixa-etária entre 04 e 06 anos de idade, o tema da aula é "profissões". Diversas crianças expõem seus projetos, desejos e fantasias para o futuro.

Dominique: - "Quando eu crescer, vou ser professora."

Duda: - "Quando eu crescer, quero ser bombeiro."

Chris: - "Eu quero ser igual minha mamãe: dona da casa."

Ariel: - "Eu quando crescer, quero ser a Barbie."

Ariel é um menino negro de 5 anos de idade, que tem preferência por brincar com o grupo de meninas da turma, sempre escolhendo, entre os brinquedos dispostos, as bonecas, panelas, roupas coloridas e salto alto para compor seus cenários de realidades e fantasias.

Quando a professora explicou à turma que a Barbie era uma boneca e não uma profissão, Ariel não se interessou por compreender.

As demais crianças, apesar da pouca idade, repreenderam Ariel, lhe informando:

- "A Barbie é loira e você é um menino preto."

Na situação de repreensão dos amigos, Ariel iniciou um processo de choro e reclamação. Para ele, não importava se a boneca Barbie não era classificada como profissão. A pergunta da professora foi: “o que você quer ser quando crescer?" E Ariel prontamente respondeu: “A Barbie.” 
Tal situação causou alvoroço na sala de aula. O tema "profissões" proposto, já não era mais relevante.

Ariel não esqueceu sua escolha para o futuro e levou sua vontade de ser a boneca mais cobiçada pelas meninas e por meninos, também, para fora da sala de aula. No recreio este foi o assunto principal. Nos corredores da unidade escolar, Ariel divulgava sua escolha. E seguiu repetindo a mesma fala e performando as ações da boneca até o momento da saída, quando anunciou para seu responsável sua intenção como projeto de vida.

Todos os profissionais da escola iniciaram uma observação mais atenta sobre o comportamento do Ariel, a partir do dia das "profissões." Suas ações espontâneas para muitos eram classificadas como absurdas.

Ariel no "trenzinho", ao se deslocar entre um espaço e outro dentro da unidade, chorava copiosamente, porque queria seguir no "trem" das meninas.

O psicólogo da unidade escolar foi notificado e orientado pela Equipe Diretiva a convocar a família do Ariel para uma "reunião urgente". Ariel então começou a ser apontado por quase todos da unidade como uma criança que necessitava de tratamento psicológico. Os argumentos dos adultos eram justificados pela preocupação com o futuro do Ariel, que segundo eles, iria sofrer nos próximos anos dentro e fora da escola. O comportamento do Ariel não foi discutido, avaliado ou compreendido. Ariel não foi acolhido. Com o passar dos dias, ele foi ignorado.

Segundo Fromm (2015), um dos autores mais lidos por Paulo Freire, alguém é um mestre na arte de amar quando apresenta três dimensões do amor, sendo estes: o "(...) conhecimento teórico, a prática e uma constante preocupação" (FROMM, 2015, apud KOHAN, 2019, p. 20). Para o autor, Paulo Freire foi este que sempre apresentou em sua vida tais gestos amorosos. Com base na psicanálise (FREUD, 1920/2006; 1929/1981), amor e ódio estão sempre imiscuídos enquanto afetos ambivalentes e compostos. O amor é a resultante desejável da constante luta pulsional. O contrário disso seria a indiferença, completamente avessa ao desejo no que se refere à relação com o outro. A indiferença possui grande potencial deletério na relação entre professores e estudantes já que, nesse caso, sequer se forma um laço educativo, pois os afetos de desligamento, o desprezo e desvalor atribuídos ao outro são predominantes. Aqui a desfusão pulsional dá lugar ao apagamento da ambivalência, quando a pulsão de morte sai vitoriosa. Neste último caso, vencem paralelamente os processos de estigmatização, exclusão e punição. A resposta dada pela escola, conforme descrito foi a da vitória de tânatos pela via da indiferença e de suas variantes repressivas e normatizantes. 
Já a amorosidade freiriana implica numa mistura entre eros e tânatos em que a ligação à vida pelo investimento afetivo no outro é maior que a destrutividade, na medida em que potencializa os sentidos criativo e sublimatório da agressividade. Para educar com base na amorosidade freiriana, não há de se excluir a agressividade, a diferença, o debate e o não. Não há problema de se dizer para Ariel: "Barbie não é profissão"; o problema é quando a escola se recusa a entender e explicar de onde vem o suposto "erro" (ou seja, de uma questão da lógica formal) para eliminar a conversa sobre diferença e sexualidade, evitando abordar a diferença inusitada de uma criança, o que poderia, na realidade, ser um momento pedagógico para todos. Ademais, para além do "erro" inusitado da resposta no que concerne aos preconceitos quanto à sexualidade, há um forte teor racista e classista embutido na resposta das crianças sobre a “impossibilidade" de um menino negro querer virar uma boneca branca.

Ariel é uma criança queer? O que é queer?

O queer como afirma Miskolci (2012) tanto do ponto de vista político como teórico surgiu das inúmeras críticas à ordem sexual advindas dos movimentos sociais emergentes na década de 1960, assim como dos movimentos pelos direitos civis de negros do Sul dos EUA, bem como do ideário produzido pela segunda onda do movimento feminista e do movimento homossexual (KARSON, 1994; KING JR, 2014; MURARO, 1999; DAVIS, 2016; SONTAG, 2007; SPARGO, 2017).

Afinal o que é ser queer?

\begin{abstract}
Queer é estranho, raro, esquisito. Queer é, também, o sujeito à sexualidade desviante homossexuais, bissexuais, transexuais, travestis e drags. É o excêntrico que não deseja ser "integrado" e muito menos "tolerado". Queer é um jeito de pensar e dizer que não aspira ao centro nem o quer como referência; um jeito de pensar e de ser que desafia as normas regulatórias da sociedade, que assume o desconforto da ambiguidade, do "entre lugares", inexcedível. Queer é um corpo estranho que incomoda, perturba, provoca e fascina (LOURO, 2008, p.30).
\end{abstract}

Hoje nas escolas, existe a necessidade de compreender que o queer vai além de um rótulo de identidade de gênero e que a teoria queer vem desconstruindo certezas do próprio conhecimento. O que sabemos e o que não queremos saber acerca da sexualidade? Que injunções narcísicas prepotentes nos provocam a desconhecer o outro, o diferente?

É importante abordar algumas associações da teoria queer com a teoria psicanalítica contemporânea (não aquela parte falocêntrica de Freud, já bastante criticada e ultrapassada em diversas epistemologias psicanalíticas).

Mesmo com diversos teóricos abordando o campo do gênero e da sexualidade a partir de uma perspectiva queer, muitos tendem a considerar as contribuições ou não das teorias 
psicanalíticas. A perspectiva entre as teorias e os estudos sobre gênero é quase sempre dualista. Aran (2009), aponta que a ausência de um necessário diálogo mais amplo e atento entre a psicanálise e a Teoria Queer, nos envolve no perigo de se voltar e permanecer em uma lógica sexista, mantendo a subordinação dos gêneros ainda à matriz heterossexual.

Os Três Ensaios Sobre a Teoria da Sexualidade, lançados por Freud em 1905 é um dos textos mais revisitados pelo autor, no qual ele se debruçou por aproximadamente 20 anos. Corroborado por seus biógrafos Gay, (2002) e Roudinesco (2014), é possível perceber a importância das reflexões de Freud (1905/2016) sobre a possível desmontagem da heteronormatividade. (SIMÕES E GONÇALVES, 2018).

No entanto, Preciado (2019), filósofo e um dos grandes nomes da Teoria Queer, gerou um movimento que abalou o mundo psicanalítico com sua intervenção na Jornada da Escola da Causa Freudiana. Sua fala foi rejeitada e, também recebeu os aplausos de muitos que realizam uma crítica contundente à psicanálise. Por outro lado, Butler (1990/2019), também um dos nomes mais conhecidos na atuação dos estudos da Teoria Queer, dialoga com a psicanálise de forma a contribuir com uma crítica que nos leve a uma aproximação entre os estudos queer e as teorias psicanalíticas, de modo que seja resgatado o lugar do pensamento psicanalítico, em particular de Freud e Lacan, entre as matrizes teóricas da teoria queer, reafirmando o caráter subversivo da concepção da sexualidade em relação à norma heterossexual. (SIMÕES E GONÇALVES, 2018).

Entendemos que há diversos desafios para articular a Teoria Queer e a psicanálise, ainda mais em um momento no qual a intervenção junto ao corpo está ao alcance de muitos. "Ironicamente, são os processos que estão transformando, de forma radical, o corpo humano que nos obrigam a repensar a alma humana" (TADEU, 2009, p. 10).

Haraway (2009), bióloga, filósofa e autora de diversos livros e artigos que trazem questões como a ciência e o feminismo para o debate atual, no seu conceito do "ciborgue", afirma que (...) "o ciborgue é uma criatura de um mundo pós-gênero: ele não tem qualquer compromisso com a bissexualidade, com a simbiose pré-edípica, com o trabalho não alienado" (HARAWAY, 2009, p. 38).

O ciborgue não sonha com uma comunidade baseada no modelo tradicional de família mesmo que, desta vez, sem o projeto edípico. “Assim, meu mito do ciborgue significa fronteiras transgredidas, potentes fusões e perigosas possibilidades - elementos que as pessoas progressistas podem explorar como um dos componentes de um necessário trabalho político" (HARAWAY, 2009, p. 45). Nesse sentido, a própria teoria queer faz a psicanálise se repensar 
dado o desafio que desperta. Psicanalistas são profissionais que eventualmente vão escutar uma criança em sofrimento por sua condição distinta. A psicanálise enquanto saber também atua no sentido da escuta e da dialogicidade, podendo escutar a família e a escola, e até acompanhar processos de transição sexual.

Ainda falando sobre fronteiras a ser ultrapassadas, em sua obra semiautobiográfica Borderlands, La Frontera: a nova mestiza, Glória Alzanduá (2021) diz que o queer é aquele que se aproxima de uma fronteira, bem como aquele que atravessa as fronteiras. Fronteira não como o que divide duas identidades supostamente fixas, mas como algo que une uma passagem de um ponto ao outro, um espaço de constante transição (ANZALDÚA, 2021). E não seria justamente essa a ideia lacaniana de nó borromeano, e de extimidade (LACAN, 1974-1975), em que dentro e fora se comunicam, consciente e inconsciente se misturam, masculino e feminino se compõem criando uma palheta de cores para a sexualidade?

\section{Queerizando a Amorosidade}

No fim dos anos 1980, surgiu nos Estados Unidos a Teoria Queer que veio possibilitar a construção de novas pedagogias que não investem apenas em uma perspectiva binária de gênero e sexualidade, se esforçando para pensar novas estratégias pedagógicas não-normativas e como um campo moderno, surgiu a Pedagogia Queer. Segundo Louro (2008), a pedagogia queer está “(...) longe de pretender atingir um sujeito ideal, assumiu um caráter inconcluso e incompleto" (p.46), tal como são as infâncias na educação infantil.

A Teoria Queer se consolidou por volta dos anos 1990 com a publicação da primeira edição do livro Problemas de Gênero da Judith Butler (1990/2019) e Glória Alzanduá foi a primeira a utilizar academicamente o termo queer, seguida por Teresa de Lauretis que se apropriou do termo ao realizar uma Conferência na Califórnia em 1990, na qual empregou a denominação Queer Theory (MISKOLCI, 2009).

O termo queer já existe há mais de quinhentos anos na língua inglesa e foi designado para nomear um conjunto de sujeitos ou corpos imprestáveis e indesejáveis, como os frequentadores da "Queer Street", famosa avenida inglesa conhecida como ponto de encontro de indivíduos não comumente aceitos pela sociedade da época, como os homossexuais, transexuais, travestis, prostitutas, devedores etc. Este termo, sem tradução clara na língua portuguesa é confundido como xingamento a quem mostra-se diferente. Queer não é um termo de fácil compreensão no Brasil. Aqui, as pessoas não se denominam queer, ao menos, não as pessoas que não têm acesso à Teoria Queer. 
O termo queer foi incorporado ao vocabulário acadêmico das diversas línguas ocidentais na medida em que a Teoria Queer se disseminou pela Europa e pela América Latina. O arcabouço teórico queer incita uma oposição ao normativo, posição que não é unicamente reservada aos gays e às lésbicas, mas acessível a qualquer indivíduo que é ou se sente marginalizado (HALPERIN, 2000). Por ser diferente, contrário a ideologias hegemônicas consideradas "normais", "corriqueiras", "usuais", "adaptativas", “dominantes” etc., porém que ferem profundamente a ética do desejo (LACAN, 1986/2008), o sujeito se "desidentifica" (MANONNI, 1987) da normatividade social vigente, uma vez que esta não comporta sua singularidade.

Segundo Spargo (2017), queer em inglês pode atuar como verbo, substantivo ou adjetivo. De insulto, o termo queer, passou a ser reivindicado e utilizado como uma expressão de transgressão, marcando uma oposição à norma.

Se a cultura queer reivindica o termo queer como adjetivo que se diferencia da relativa
respeitabilidade de gay e lésbica, então podemos dizer que a teoria queer utiliza o
termo queer como verbo que põe em dúvida as pressuposições sobre ser e agir de
modo sexual e sexuado. Em teoria, queer está incessantemente em desacordo com o
normal, a norma (...) é categoricamente excêntrico, a-normal (SPARGO, 2017, p. 36).

Em 2001, Guacira Lopes Louro publicou um artigo intitulado "Teoria Queer: uma política pós identitária para a educação." Foi um marco para o início das discussões dos estudos queer no Brasil.

Na língua portuguesa não temos uma palavra que dê conta de um significado ou tradução para o termo queer. Por isso, muitos teóricos e pesquisadores de diversos países e línguas continuam utilizando a palavra queer nos seus estudos. Ainda assim, há autores, principalmente nos países latinos, que se interessam em pensar o queer de forma mais local, tais como: Bento (2014) que opta pela terminologia "teoria transviada", San Martin (2011) prefere usar "teoria cuir" e Pelúcio (2014) provocativamente adota “teoria cu”. Esses são alguns dos exemplos de inspiração (COLLING, 2016) dos autores numa ideia de diferença radical.

Em diversos estudos e pesquisas acadêmicas, encontramos além da palavra queer, o uso do termo queerizar ou queerizando ${ }^{i i i}$, como forma de ampliar a discussão e perspectiva da prática pedagógica normativa para o campo das multiplicidades dos sujeitos, reconhecendo as transformações das experiências ao longo dos avanços da cultura.

Queerizar é verbo, é ação para problematizar e transviar sujeitos, desestabilizando-os dos lugares que confortavelmente ocupam (HALPERIN, 2000), seja no sentido de serem 
reconhecidos os que assim se identificam, seja para desconstruir preconceitos e reconhecer a diferença do outro.

Segundo Louro (2008), a ressignificação da palavra queer, trouxe uma utilização do termo como tentativa de não mais utilizá-la de forma pejorativa e sim de dotá-la de diversos significados, assumindo, também, seu aspecto político. Nesse sentido, queer não se refere a uma teoria estática nem prioritariamente reivindicatória, mas de um trabalho dinâmico de construção constante com o outro, reconhecido na sua diferença. Conforme define o filósofo Alain Badiou (2011) em seu recente Éloge de l'amour, amar é viver na diferença. Afinal, não seria essa a função sublime do amor? Em algum sentido, pela filiação marxista, essa noção filosófica do amor na diferença combina com a concepção de amorosidade no cerne da luta por uma pedagogia da autonomia freiriana (FREIRE, 1996).

O ponto central da Teoria Queer dialoga com a Filosofia da Diferença ao questionar a criação da realidade a partir da "produção de subjetividades" utilizáveis/rentáveis, assinalando novos caminhos para o pensamento, logo, avaliando até que ponto queremos conservar algo ou não sobre o que conhecemos ou desconhecemos.

Jamais encontraremos o sentido de alguma coisa (fenômeno humano, biológico ou até mesmo físico) se não sabemos qual é a força que se apropria de uma coisa, que a explora, que dela se apodera ou nela se exprime. Um fenômeno não é uma aparência, nem mesmo uma aparição, mas um signo, um sistema que encontra seu sentido numa força atual. (DELEUZE, 1976, p. 5)

Ao olhar para a relação da criança queer com o mundo e ao avaliar a relação dos adultos com o mundo escolar dela, é possível perceber formas muito endurecidas de opressão e de desumanização. Com efeito, a subjetividade tradicionalmente produzida na escola é hetero e biologicamente teleguiada para "nascer, crescer, reproduzir e morrer", enfim, para se adaptar à sociedade tal como ela se apresenta, e não para questionar, se rebelar, transformar o que está dado a partir da diferença presente em si mesma. Nesse contexto, a criança queer não tem lugar, ou seja, é atópica por ser atípica. A partir deste entendimento e dos processos pelos quais passa essa criança no espaço escolar, é necessário compreender como são narradas suas vivências, buscando observar se ela experimenta algum tipo de mal-estar por ser vista não apenas como uma criança que necessita de apoio e respeito e sim como um ser que, fora da norma, têm suas histórias muitas vezes silenciadas na educação infantil.

\section{Amorosidade enquanto transgressão}


O educador e filósofo Paulo Freire, apesar de ser mais conhecido no uso de suas metodologias no campo educacional com adultos, em muito nos inspira a trabalhar com seus conceitos também no campo das infâncias.

Em seu conceito de amorosidade é possível buscar o entendimento sobre como o diálogo imbuído de uma escuta sensível pode auxiliar o professor da educação infantil na elaboração de um discurso que vá além da afirmativa "somos todos iguais", consciente ou inconscientemente reprodutora da lógica de que a criança queer necessita se adequar à norma escolar.

Como posto por Fernandes (2018):

\begin{abstract}
A amorosidade freiriana que percorre toda a sua obra e sua vida se materializa no afeto como compromisso com o outro, que se faz engravidado da solidariedade e da humildade, (...) tarefa difícil que desafia uma solidariedade e humildade não como submissão, mas como possibilidade de que a verdade também possa estar com o outro, em um emaranhado que envolve respeito como uma categoria de acolhimento das diferenças (p. 69).
\end{abstract}

Paulo Freire nos convida a pensar na criança como ser histórico e produtor de cultura (FREIRE, 2000). Com a concretude da produção do sentido e do sentir amorosidade como uma potencialidade e uma capacidade humana que remete a uma condição de finalidade no mundo e com o mundo, a amorosidade partilhada proporciona dignidade coletiva (STRECK, 2007).

Nas ações tradicionais que são diariamente desmascaradas na escola pela possibilidade de conceber novas ideias distantes de regras, normas e padrões, a escola pública pode oportunizar o ensino e o debate sobre essas diferenças ao seu variado público, na busca por uma educação que contemple a diversidade, se afirmando contra qualquer forma de discriminação. Tais orientações se encontram nos Parâmetros Curriculares Nacionais (1998) ${ }^{\text {iv }}$ no que concerne ao tema transversal "Orientação Sexual:"

A escola, ao propiciar informações atualizadas do ponto de vista científico e explicitar os diversos valores associados à sexualidade e aos comportamentos sexuais existentes na sociedade, possibilita ao aluno desenvolver atitudes coerentes com os valores que ele próprio elegeu como seus (p. 83).

Desde a publicação dos Parâmetros Curriculares Nacionais houve uma significativa ampliação do debate sobre sexualidade e educação sexual nas escolas. As discussões sobre gênero e igualdade, tornaram-se presentes e o combate à homofobia e a defesa dos direitos LGBTIA+ passaram a fazer parte do discurso social e jurídico. Por volta do ano de 2014, se deu o início das discussões para a elaboração da BNCC - Base Nacional Comum Curricular, a “sucessora" dos PCN's - Parâmetros Curriculares Nacionais. Os documentos são distintos, 
porém é possível constatar que a BNCC chegou na contramão dos PCN's, imbuída da onda de conservadorismo que inundou o país (MONTEIRO; RIBEIRO, 2020).

A Base Nacional Comum Curricular carrega em seu texto atualmente, várias intencionalidades voltadas aos interesses políticos, religiosos e mercadológicos e no lugar de estimular o exercício da reflexão sobre as diferenças, optou por retirar temas e termos que caminham em sentido oposto à ideologia hegemônica (PICOLI, 2020). Trata-se hoje, de um documento que censura as singularidades de cada um, impondo um padrão a ser seguido em um país tão diverso, como o Brasil.

Na sua concepção, a BNCC leva ao ambiente escolar, uma percepção restrita e que censura as singularidades, como se a escola fosse um espaço no qual fosse possível desenvolver (...) "um modelo de aluno que corresponde à norma social: um menino ou uma menina com as características de gênero, heterossexualidade e estrutura familiar compatíveis com o que é esperado pela sociedade" (FRANÇA; CALSA, 2011, p. 111).

"Uma pedagogia e um currículo queer se distinguiriam de programas multiculturais bem-intencionados, em que as diferenças (de gênero, sexuais ou étnicas) são toleradas ou são apreciadas como curiosidades exóticas" (Louro, 2008, p. 48). Desta forma, uma pedagogia baseada na Teoria Queer estaria voltada para um processo de produção e valorização das diferenças e trabalharia com a instabilidade de todas as identidades. Uma proposta queer nas escolas faria com que as diferenças fossem percebidas.

É urgente continuar levando para a escola a discussão sobre as diferenças, o que vai ao encontro do conceito de amorosidade e seus desdobramentos dentro e fora da escola, sobretudo incorporado a uma práxis contemporânea que venha a subsidiar reflexões do professor sobre o sentido e o sentir da amorosidade como modo de acolhimento da criança, independente da forma na qual ela se apresenta. Mas como viabilizar esses debates se os próprios professores estiverem alijados de uma possibilidade de reconhecimento da sexualidade divergente, traumatizados por uma normatividade sexual hegemônica que os torna ainda mais avessos à liberdade e à verdade sexual do Outro? Embora não pretendamos responder diretamente a essa questão, haja vista a complexidade da imbricação entre psicanálise, estudos queer e amorosidade, observamos a potência da liberação da palavra e da escuta atenta ao outro, em grande parte, correndo no mesmo sentido da dialogicidade freiriana, em que afetos não são sumariamente negados, recusados ou foracluídos. A abordagem psicanalítica compreende que a estrutura subjetiva vai sempre além da fixação em identidades rígidas, embora reconheça e considere justa a reparação reivindicada por movimentos identitários (AUTOR et al., 2017). O 
eu pode ser fluido, em constante transformação, caso se permita e queira, o que também não precisa ser uma regra, posto que ninguém é obrigado a ser queer, embora deva respeitar quem o é ou quem queira ser.

Na concepção de Butler (1990/2019), a identidade não tem fim, se reconstrói constantemente (mostrando certa consonância com uma visão psicanalítica sobre a subjetividade). Em sua obra "Problemas de Gênero", a autora descreve os processos pelos quais a identidade é construída no interior da linguagem e do discurso. As instituições, tais como a escola no seu discurso e nas suas práticas, ao determinar sexo, sexualidade e gênero cria e/ou remarca concepções que orientam as relações vida afora. Trata-se de formas de poder, questionadas pela autora:

A própria noção de diálogo é culturalmente específica e historicamente delimitada, e mesmo que uma das partes esteja certa de que a conversação está ocorrendo, a outra pode estar certa de que não. Em primeiro lugar, devemos questionar as relações de poder que condicionam e limitam as possibilidades dialógicas. (p.36)

Como não associar essa crítica aos recentes ataques à educação, por exemplo, quando visam proibir que se fale de gênero, como é o caso do Projeto Escola sem Partido? (vide REIS, 2018). Na educação infantil as crianças subvertem e questionam as identidades e, algumas delas, ofertam a possibilidade de que a realidade seja vista não a partir da identidade, mas da diferença. O que a criança queer gera nos adultos é instável, pois tendo diferenças nela, não se pode estabelecer nenhuma identidade, já que ela está em construção sempre. Por outro lado, incomodam os adultos, pois despertam as partes recalcadas e clivadas presentes em seu inconsciente.

Conversar, dialogar e ouvir é também responsabilidade da escola para que a criança consiga entender seu papel como cidadã, para que possa se aceitar e aceitar os outros conforme suas idiossincrasias, evidentemente na medida em que não firam o direito coletivo. Desse modo, é necessária a compreensão de que a criança queer combate intensamente a dominação e a discriminação do seu modo de viver na escola, principalmente, perante seus professores.

$\mathrm{O}$ conceito de amorosidade remete à discussão da necessidade do acolhimento da criança queer e das relações que devem ser permeadas no cotidiano escolar. Poucos são os professores da educação infantil que enfrentam o processo de despertar nas crianças variadas vivências e experiências transformadoras, questionando o que é dado. Dialogar e questionar conceitos antigos e enrijecidos pode ser percebido como uma ameaça. Ao abordar diferenças teme-se levá-las ao fracasso, seja no desenvolvimento cognitivo, afetivo ou social. Mas não há como se desenvolver sem percalços, sem erros ou um certo sofrimento por perda de realidades 
que já não nos servem mais. No início do século XX, chegou-se a pensar que a psicanálise causaria um "incêndio" na Educação, na medida em que os pressupostos pedagógicos seriam repressivos e a repressão essencialmente traumática (FREUD, 1909/1991; MILLOT, F. 1997). Contudo, não há amadurecimento sem trauma, não há educação sem perda de gozo, não há cultura sem renúncia pulsional (FREUD, 1929/1981), de modo que alguma perda na diferença, na vizinhança com o direito do outro, se faz necessária, logo aquilo que é visto como trauma também pode conter um teor estruturante. A relação de investimento libidinal no outro é sempre equívoca e comporta riscos, mas sem isso, sem amorosidade, não há vida que valha a pena ser vivida.

É preciso empenho para empregar e explorar filosoficamente a palavra amorosidade, tão evidente nas obras da pedagogia freireana. A amorosidade sugere uma filosofia da vida prática onde é eminente o reconhecimento da representação da criança como ser social e histórico formado por múltiplas possibilidades de ser e estar no mundo. Reconhecer a necessidade de uma ação dialógica entre professores e estudantes, principalmente, crianças, como fundamento da possibilidade da relação amorosa do "ser mais", mostra-se com uma verdade dotada de potência que os professores e os estudantes devem buscar em atitudes, para fazer emergir uma educação consciente, e sobretudo, amorosa (FREIRE, 1996).

Freire (2013), aponta a necessidade de o professor buscar a vocação ontológica e histórica do "ser mais", que o habilita a definir a sua vocação como a do ser que luta pela humanização. Para tanto faz-se necessário, além dos conhecimentos teóricos e legais que fundamentam a prática do professor da educação infantil, a intervenção de uma ação dialógica reflexiva e amorosa nas condições concretas no cotidiano com a criança.

Tomando a amorosidade como princípio instituído no ambiente escolar, e até mesmo nos documentos norteadores das unidades, ao exercer a dialogicidade como princípio é possível vislumbrar o que Freire nos deixou como caminho em uma sábia emergência da abertura ao outro, pela troca atenta e participativa. Existe uma aliança entre a amorosidade e o diálogo, pois quando há diálogo, há amorosidade. E não existe diálogo sem escuta e aceitação da realidade do outro.

O diálogo ocorre através do encontro. No lugar da professora encerrar o tema "profissões" na turma de educação infantil, como relatado na introdução desse texto, no momento do surgimento da oportunidade de explorar as diferenças, a turma e toda a escola poderiam ser levadas a um diálogo entre os iguais ou entre os diferentes, entre as crianças e os adultos, de modo a despertar a valorização das diferenças. Não há necessidade de igualdade de 
princípios para que o diálogo ocorra como uma escuta amorosa e solidária. É possível o diálogo com o diferente. Não se trata de ter que mudar o outro e sim de reconhecer o outro em toda a sua existência. Evidentemente, isso não quer dizer uma aceitação incondicional de tudo o que a criança diz ou faz, posto que há normas que devem ser respeitadas por todos. No entanto, no que tange à sexualidade, há normas caducas que precisam ser derrubadas, pois são opressoras, excessivas e cujo sentido só existe para a manipulação e exploração das subjetividades dentro de uma heteronormatividade capitalística. No que concerne à ética, esses valores estão deveras ultrapassados, mesmo que ainda sejam desastrosamente vigentes na prática, em muitas famílias. Nesse sentido, existem inclusive novas normas mais abrangentes e compreensivas:

Outro ponto a ser considerado para as intervenções do professor nas situações de manifestação de sexualidade de seus alunos em sala de aula é o referente aos valores a ela associados. O professor não deve emitir juízo de valor sobre essas atitudes, e sim contextualizá-las. O mesmo vale para as respostas que oferece às perguntas feitas por seus alunos (BRASIL, 1998, p. 103).

Na reivindicação de uma educação baseada no acolhimento de todos sem distinção, é preciso considerar que "a humanização em processo, é a práxis, que implica na ação e na reflexão sobre o mundo para transformá-lo" (FREIRE, 2013, p. 93).

No universo da práxis de Freire, seu legado de amorosidade está em seus escritos e na forma da existência de suas práticas educativas, nos dando diariamente pistas para o fazer pedagógico mostrar-se mais humanizado e acolhedor com todas as crianças, independente do que elas trazem em seus corpos, ideias e fantasias.

É importante salientar que a amorosidade não é ingênua, romântica e nem abstrata. "É nesse contexto que o amor está armado, em defesa do direito de amar" (KOHAN, 2019, p. 135).

Não é possível já na educação infantil definir os próximos passos de uma criança. Porém é possível e necessário acolhê-la com uma visão de mundo de que ali está alguém que deseja ser exatamente quem é e como é, desidentificada dos padrões de gênero e sexualidade instituídos. Isso não tem nada de errado, para além de uma adequação classificatória do que seria um conjunto, uma profissão, uma lógica ou um padrão biológico supostamente a ser seguido, esses padrões sim, muitas vezes, ultrapassados e potencialmente violentos.

\section{Considerações Finais}

A tentativa, ao propor essa escrita, foi de colocar em diálogo os pressupostos dos estudos queer e da amorosidade, com esparsos pressupostos da filosofia da diferença e da psicanálise como busca de uma Pedagogia da Amorosidade Queer, acolhedora das diferenças. 
Nesse contexto ainda incerto de busca de novas pedagogias, o papel do professor da educação infantil precisa ser repensado. Segundo Gadotti (1998) é necessário que o professor se assuma enquanto um profissional do humano, social e político, tomando partido e não sendo omisso e neutro. Afinal, a amorosidade é política e guerreira, também, ensina em defesa do direito de ensinar (KOHAN, 2019).

Posicionando-se não mais como neutro nas situações como a citada no relato no início desse texto, o professor pode ascender usando a amorosidade como instrumento de luta e visão de uma consciência crítica que supere o senso comum de rejeitar, silenciar e ignorar uma criança que apenas se mostra como ela verdadeiramente é, superando seus medos e não mais desconsiderando as diferenças.

Toda teoria pedagógica é fundamentada em uma filosofia. A filosofia ao expressar sua concepção de ser humano e de mundo deu sentido à pedagogia, determinando os métodos de suas ações educativas (HAYDT, 1997). Toda escolha é o reflexo de uma filosofia de vida. Ao escolher se enveredar pela área da educação, o professor necessita assumir que não existe uma educação com ações neutras. Sempre será necessário tomar partido e assumir uma posição.

Mesmo sem a consciência do que acontece ao seu redor, a criança queer estabelece um devir. Segundo Deleuze (1997), devir seria, justamente, aquilo que se instala entre uma sensação e outra, correspondendo ao plano das intensidades e, portanto, marcando uma linha de fuga a transitar. (DELEUZE, 1992).

A criança queer utiliza esse impulso - que resiste de modo a produzir e apresentar forças que se encontram em ação no seu corpo - para driblar o poder dos adultos e criar modos de vida forjados como resistência às formas dos adultos de governar os que são considerados fora da norma, impondo uma subjetividade adaptativa geradora de enorme sofrimento psíquico à proporção que desconhece a singularidade do desejo infantil.

Streck traz as seguintes palavras de José Martí “(...) a educação há de ir para onde vai a vida, para afirmar em seguida que: se a educação precisa ir para onde vai a vida ela deve em primeiro lugar, ir aonde estão as pessoas" (STRECK 2007, p. 19). Amorosidade na visão freireana é vida, vida com pessoas e uma condição assentada no diálogo que tanto exige amor e confiança, mostrando-se sempre como caminho (FREIRE, 1996). Freire (2013) ensinou que quem ama não desiste. Assim, o papel do professor é o de escutar, pacientemente e criticamente a criança, falando com ela e não para ela.

O professor ora ensina, ora aprende. Ele também é aprendiz que necessita ter a consciência do próprio inacabamento. "Onde há vida, há inacabamento” (FREIRE, 1996, p. 
50). Aquele que conduz a criança no processo de aprendizagens não pode deixar de aprender e de buscar a amorosidade que se faz como caminho.

O diálogo, cada vez menos presente nas relações, não pode existir na ausência de um amor profundo pelo mundo e pelas pessoas. Já dizia Freire (2013), o amor é um ato de coragem. Com uma nova perspectiva amorosa e dialógica, caminhos podem ser indicados com pretensões de se aventurar por uma práxis que destaca a necessidade de afirmar um conhecimento sensível ao aprimoramento de nossos afetos às crianças dissidentes que povoam a escola.

A diversidade sexual abordada dentro da escola, se refere à “(...) prática de liberdade, na medida em que os limites de nosso pensamento deverão ser transcendidos em nome de outras possibilidades tanto de conhecer como de amar" (CÉSAR, 2009, p. 49).

$\mathrm{O}$ encontro que se dá diariamente nas escolas entre meninxs ${ }^{\mathrm{v}}$ e professorxs é como um devir-criança que tem a potência de gerar novos caminhos e que seja de compromisso com a produção de novos modos de existência da educação como prática da diferença, da liberdade, do respeito e da amorosidade.

\section{Referências}

ANZALDUÁ, G. Borderlands / La Frontera: la nueva mestiza. Madrid: Capitán Swing Libros, 2021. E-book Kindle.

ARÁN, M. A psicanálise e o dispositivo diferença sexual. Revista Estudos Feministas, ano 17, n. 3. Florianópolis, set./dez. 2009. Disponível em:

$<$ https://www.scielo.br/scielo.php?pid=s0104-

026x2009000300002\&script=sci_artex\&tnlg=pt>. Acesso em: 18 abr. 2021.

AUTOR et al., 2017.

BRASIL. Ministério da Educação e do Desporto. Parâmetros Curriculares Nacionais: terceiro e quarto ciclos: Orientação Sexual. Brasília: MEC SEF, 1998. Disponível em: 〈http://portal.mec.gov.br/seb/arquivos/pdf/livro01.pdf>. Acesso em: 12 abr. 2021.

BRASIL. Secretaria de Educação Fundamental. Base Nacional Comum Curricular. Brasília: MEC, 2018. Disponível em: <http://basenacionalcomum.mec.gov.br/abase/>. Acesso em: 16 abr. 2021.

BENTO, B. A reinvenção do corpo: sexualidade e gênero na experiência transexual. Rio de Janeiro: Garamond, 2006. 
O que pode uma teoria? Estudos Transviados e a Despatologização das Identidades Trans. Revista Florestan. ano 1, n. 2, p. 46-66, nov. 2014. Disponível em: http//www.revistafloestan.ufscar.br/index.php/florestan/article/view/64>. Acesso em: 12 abr. 2021.

BUTLER, J. Corpos que importam: os limites discursivos do sexo. São Paulo: Editora n-1 Edições, 2019.

. Problemas de Gênero: feminismo e subversão da identidade. Rio de Janeiro:

Civilização Brasileira, 1990/2019.

CÉSAR, M. Gênero, sexualidade e educação: notas para uma "Epistemologia". Educar em Revista, Curitiba, n. 35, p. 37-51, 2009. Disponível em: <https://www.scielo.br/scielo.php?pid=s0104-4060200900030004\&script=sci_arttext $>$. Acesso em 12 abr. 2021.

COLLING, L. (Org). Dissidências Sexuais e de Gênero. Salvador: EDUFBA, 2016.

BADIOU, A. (auteur); TRUONG, N. (interviewer). Éloge de l'amour. Paris: Flammarion, 2011.

DAVIS, A. Mulheres, Raça e Classe. São Paulo: Boitempo, 2016.

DELEUZE, G. Crítica e clínica. São Paulo: Editora 34, 1997. . Nietzsche e a Filosofia. Rio de Janeiro: Editora Rio, 1976.

DELEUZE, G; GUATTARI, F. O que é a filosofia? Rio de Janeiro: Editora 34, 1992.

FERNANDES, C. Amorosidade. In: STRECK, D. R; REDIN, E; ZITKOSKI, J. J. (Orgs). Dicionário Paulo Freire. Belo Horizonte: Autêntica, 2018. p. 69-71.

FRANÇA, F. F; CALSA, G. C. Gênero e sexualidade na formação docente: desafios e possibilidades. Sociais e Humanas, Santa Maria, v. 24, n. 02, jul./dez. 2011. Disponível em: https://periodicos.ufsm.br/sociaisehumanas/article/view/2828/2858>. Acesso em: 17 abr. 2021.

FREIRE, P. Educação como prática da liberdade. Rio de Janeiro. Paz e Terra, 2011.

e Terra, 1996.

Pedagogia da Autonomia: saberes necessários à prática educativa. São Paulo: Paz Pedagogia da Esperança: um reencontro com a pedagogia do oprimido. Rio de Janeiro: Paz e Terra, 2014.

Pedagogia da Indignação. São Paulo: Editora Unesp, 2000.

Pedagogia do Oprimido. Rio de Janeiro: Paz e Terra, 2013.

Revista Interinstitucional Artes de Educar. Rio de Janeiro, V.7, N.2 - pág. 1016-1036 mai-ago de 2021: "Dossiê História das Mulheres e Educação" - DOI: 10.12957/riae.2021.63448 
FREIRE, P; FAUNDEZ, A. Por uma pedagogia da pergunta. Rio de Janeiro: Paz e Terra, 1985.

FREUD, S. (1905). Três ensaios sobre a teoria da sexualidade. Obras completas, V.6. São Paulo: Companhia das Letras, 2016.

. (1909). Correspondance avec le pasteur Pfister. Paris: Gallimard, 1991.

. (1920). Além do princípio do prazer. Escritos sobre a Psicologia do Inconsciente,

V.2. Rio de Janeiro: Imago, 2006.

. (1929). Le malaise dans la civilisation. Paris: PUF, 1981.

FROMM, E. A arte de amar. São Paulo: Martins Fontes, 2015.

GADOTTI, M. Pedagogia da práxis. São Paulo: Cortez, 1998.

GALIAN, C. V. A. Os PCN e a elaboração de propostas curriculares no Brasil. Cadernos de Pesquisa, São Paulo, v. 44, n. 153, jul./set. 2014. Disponível em:

https://www.scielo.br/scielo.php?script=sci_arttext\&pid=S010015742014000300009\&lng=pt \&tlng=pt>. Acesso em: 16 abr. 2021.

GAY, P. Freud: uma vida para o nosso tempo. São Paulo: Companhia das Letras, 2002.

HALPERIN, D. San Foucault: para uma Hagiografía Gay. Córdoba: Cuadernos de Litoral, 2000.

HARAWAY, D. Manifesto ciborgue: Ciência, tecnologia e feminismo socialista no final do século XX. In: HARAWAY, D; KUNZRU, H; TADEU, T. (Org). Antropologia do ciborgue: as vertigens do pós-humano. Belo Horizonte: Autêntica, 2009.

HAYDT, C. R. C. Curso de Didática Geral. São Paulo: Ática, 1997.

LACAN, J. (1966). Escritos. Rio de Janeiro: Jorge Zahar, 1998.

. Le seminaire, livre XXII: RSI (1974-1975). Disponível em:

lutecium.org/2020/07/jacques-lacan-seminaire-xxii-r-s-i-1974-1975/10103>. Acesso em: 22 abr. 2021.

Zahar, 2008.

(1956-1960) O seminário, livro 7: a ética da psicanálise. Rio de Janeiro: Jorge

LAJONQUIÈRE, L. Infância e ilusão (psico)pedagógica. Petrópolis: Vozes, 2009.

LOURO, G. L. O corpo educado: pedagogias da sexualidade. Belo Horizonte: Editora Autêntica, 2018.

. Teoria Queer: uma política pós-identitária para a educação. Revista Estudos

Feminista, Florianópolis, v. 9, n. 2, 2001. Disponível em: https://www. 
scielo.br/scielo.php?pid=s0104-026x2001000200012\&script=sci_arttex\&tnlg=pt $>$. Acesso em: 09 abr. 2021.

Um corpo estranho: ensaios sobre sexualidade e teoria queer. Belo Horizonte:

Autêntica, 2008.

MANNONI, O. (1987). "A desidentificação" in As identificações na teoria e na clínica psicanalíticas (Mannoni et al.). Rio de Janeiro: Rélume-Darumá, 1994.

MILKOSCI, R. A Teoria Queer e a Sociologia: o desafio de uma analítica da normalização. Sociologias, Porto Alegre, ano 11, n. 21, p. 150-182, jan./jun., 2009. Disponível em: <www.scielo.br/scielo.php?pid=S1517-45222009000100008\&script=sci_arttext\&tlng=pt $>$. Acesso em: 09 abr. 2021.

MILKOSCI, R. Teoria Queer: um aprendizado pelas diferenças. Belo Horizonte: Autêntica, 2012.

MOITA LOPES, L. P; FABRÍCIO, B. F. Desestabilizações queer na sala de aula: táticas de guerrilha e a compreensão da natureza performativa dos gêneros e das sexualidades. In.: PINTO, J. P; FABRÍCIO, B. F. (Orgs). Exclusão social e microresistências: a centralidade das práticas discursivo-identitárias. Goiânia: Cânone editorial, 2013.

MONTEIRO, S. A. S; RIBEIRO, P. R. M. Sexualidade e Gênero na atual BNCC: possibilidades e limites. Pesquisa e Ensino, Barreiras, v. 1, e202011. 2020. Disponível em: https://revistas.ufob.edu.br/index.php/pqe/article/view/626>. Acesso em: 16 abr. 2021.

MURARO, R. M. Memórias de uma mulher impossível. Rio de Janeiro: Rosa dos Tempos, 1999.

KARSON, J. The Civil Rights Movement. Michigan: Greenhaven Press, 2005. Livraria José Olympio, 1994.

KING JR, M. L. A Autobiografia de Martin Luther King Jr. Organização Clayborne Carson. Tradução de Carlos Alberto Medeiros. 1ª edição. Rio de Janeiro: Zahar, 2014

KOHAN, W. Paulo Freire, mais do que nunca: uma bibliografia filosófica. Belo Horizonte: Vestígio, 2019.

PELÚCIO, L. Traduções e Torções ou o que se quer dizer quando dizemos queer? Revista de Estudos Indisciplinares em Gêneros e Sexualidades, Salvador. v. 1, n. 1, p. 68-91. maio/out. 2014. Disponível em:

<https://periodicos.ufba.br/index.php/revistaperiodicus/article/view/10150>. Acesso em: 12 abr. 2021.

PICOLI, B. A. Base Nacional Comum Curricular e o canto da sereia da educação normalizante: a articulação neoliberal-neoconservadora e o dever ético-estético da resistência. Revista de Estudios Teóricos y Epistemológicos en Política Educativa, v. 5, e2015036. 2020. Disponível em: https://revistas2.uepg.br/index.php/retepe/article/view/15036>. Acesso em 17 abr. 2021. 
PRECIADO, P. B. Intervención en las Jornadas No 49. de la École de la Cause Freudienne: Mujeres em Psicoanálisis. Disponível em: $<$ https://drive.google.com/file/d/1iM3OR38hhCkHSJVboiqW3rmQIC0rRak9/view>. Acesso em: 18 abr. 2021.

. Manifesto Contrassexual. São Paulo: Editora n-1 Edições, 2014.

REIS, M. S. J. Políticas educacionais para as relações de gênero: uma análise sobre o município do Rio de Janeiro. Dissertação de Mestrado em Educação. Universidade Federal Fluminense, 2018.

ROUDINESCO, É. Sigmund Freud en son temps e dans le nôtre. Paris: Seuil, 2014.

SAN MARTIN, F. R. Diga “queer” con la lengua afuera: sobre las confusiones del debate latino-americano. In: Coordinadora Universitaria por la Disidencia Sexual. Por un feminismo sin mujeres fragmentos de un segundo circuito disidencia sexual. Santiago: Territores Sexuales Ediciones, 2011.p. 59 -75. Disponível em: <diga_queer_con_la_lengua_afuera.pdf (d1wqtxts1xzle7.cloudfront.net)>. Acesso em: 4 abr. 2021.

SIMÕES, A; GONÇALVES, G. A. Labirintos da sexualidade: convergências e dissonâncias entre psicanálise e a teoria queer na atualidade. Revista Ágora, Rio de Janeiro. v. XXI, n. 1, p. 12-22. jan/abr. 2018. Disponível em: 〈https://www.scielo.br/pdf/agora/v21n1/1809-4414agora-21-01-12.pdf $>$. Acesso em: 16 abr. 2021.

SONTAG, S. Doença como metáfora: aids e suas metáforas. São Paulo: Companhia das Letras, 2007.

SPARGO, T. Foucault e a teoria queer: seguido de Ágape e êxtase: orientações pósseculares. Belo Horizonte: Autêntica, 2017.

STRECK, D. R. (Org). Educação em nossa América - José Martí. Ijuí: Editora UNIJUI, 2007.

TADEU, T. Nós, ciborgues: o corpo elétrico e a dissolução do humano. In: HARAWAY, D;

KUNZRU, H; TADEU, T. (Org.). Antropologia do ciborgue: as vertigens do pós-humano. Belo Horizonte: Autêntica, 2009.

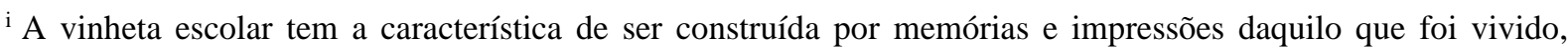
portanto, portam um caráter ficcional inerente aos processos mnemônicos. Essa metodologia de pesquisa é pensada a partir de uma práxis psicanalítica.

ii Para nomear as crianças apresentadas na vinheta escolar, utilizamos nomes fictícios ditos "unissex" no sentido de preservar suas identidades e de colaborar com a perspectiva de que nomes ditos femininos/masculinos, nem sempre contribuem para pensar a subjetividade e a invenção das maneiras de viver, ser e estar no mundo das crianças.

iii Adotamos aqui a forma verbal do termo queer, ampliando assim o seu escopo e enfatizando o seu aspecto de agenciamento de novas formas de devir (HALPERIN, 2000).

iv Parâmetros Curriculares Nacionais é um documento da década de 1990, que atuou no sentido de uniformizar o currículo nacional da educação básica (GALIAN, 2014).

" Estamos utilizando o " $x$ " no lugar dos artigos feminino/masculino no parágrafo final deste trabalho, como uma forma de destacar que nem sempre é devido determinar a priori o gênero da criança que acompanha as ações educativas no espaço escolar. Afinal, uma das intenções desse texto é repensar, a partir da Teoria Queer, a leitura dimórfica da crítica sobre os sujeitos e os estudos da "linguística queer", um campo relativamente novo no Brasil,
} 
vem se mostrando interessado em investir nas relações entre a linguagem e a sexualidade (MOITA LOPES; FABRICIO, 2013). 